\title{
Readiness of military personnel for high intensity combat training course
}

\author{
Liana Plavina, Silva Smagare, Andris Cakstins, and Silvija Umbrasko
}

Rīga Stradinsš University, Department of Morphology, Institute of Anatomy and Anthropology, Riga, Latvia

\begin{abstract}
High standards of physical ability and health are essential for Military personnel and its career. Training of military personnel in field conditions is an essential process. The aim of the study was to evaluate readiness of cadets to high physical load during the combat training course (CTC). We carried out the following: evaluated posture status, analysed anthropometric characteristics, controlled parameters of musculoskeletal system such as muscle tone, muscle strength characteristics, and provided Nordic Questionnaire list containing a figure of Human Body, where a respondent marked the regions of musculoskeletal disorder (pain). All subjects gave their informed consent to the protocol approved by the local Medical Ethics Committee of Rīga Stradinšs University for biomedical research. Combat training course has duration of ten days and includes various physical, tactical, and psychological activities in military conditions that are a compulsory part of study process in National Defence Academy of Latvia. Cadets are facing complex challenges in tactical situations where they can approve their physical abilities, endurance and psychological persistence. They have dietary and sleeping deprivation during the course. We provided standardized Nordic Questionnaire for analysis and evaluation of musculoskeletal disorders in the study group and indicated main problematic regions with musculoskeletal symptoms. The general health status of participants was checked by medical specialists in military Medical Centre and advanced examination was done by Sports medicine doctor. The aim of the study is to analyse the posture status, foot status, to make muscle functional tests that allow managing pre-courses training program for CTC participants and optimizing adaptation of participants of the course to field condition of military training. Evaluating musculoskeletal symptoms cadets indicated that main problematical regions were lower back and knee. In 77\% (42/54) of cases cadets with lower limb hypertonus had asymmetric posture in frontal plane. Analysis of anthropometric characteristics showed that body mass index changes were in the interval from 21.34 to 33.24 . BMI value for $32.2 \%$ of participants corresponded to the standards of WHO recommendations. Analysis of posture and foot status was important for provision of preventive measures and reduction of the risk of health disorders related to high physical load in military environment. Persons with expressed asymmetry of posture and foot during dynamic load and static load can have overstress with high risk of health disorders, musculoskeletal pathology and psychological overload.
\end{abstract}

Key words: anthropometric characteristics of military personnel, posture disorders, muscular functional tests data. 


\section{Introduction}

High standards of physical fitness and health are essential for Military personnel and its career. Training of military personnel in field conditions is an essential process. We have carried out evaluation of health status of participants of combat training course (CTC) that is a compulsory part of study process in National Defence Academy of Latvia. We made evaluation of posture analysis, foot status analysis, muscle function testing, which can help to manage pre-courses training program for CTC participants and optimize adaptation of participants of CTC to field conditions of military training. Military operational stress in combination with physical exertion, sleep restriction and dietary insufficiency during the CTC demanded participants' adaptation and adjustment to a changing military environment. Combat training course has duration of ten days and includes various physical, tactical, psychological activities in military conditions. Military instructors ensure control, evaluation and training the readiness and resiliency of participants of CTC. Cadets face challenges and train their physical fitness and endurance, as well as psychological approach to the tactical situation. They have dietary and sleeping deprivation during the CTC. Military exercise outcomes depend on physical fitness, aerobic fitness, muscular strength, health capacity, knowledge and practice [1]. Physical training, physical preparedness and endurance have influence on individual ability to withstand stressors [2-4]. Environmental factors have impact on stress tolerance and injury risk regarding the gender [5]. Risk of musculoskeletal injuries also depends on physical fitness $[6,7]$. Sleep restriction and limitation of adequate rest have negative impacts on cadet's reaction time and decision making, which may result in making mistakes $[8,9]$. Cold stress or extreme heat in combination with physical exercises can have effect on cardiovascular and endocrine function and decrease tactical performance $[10,11]$. Musculoskeletal disorders and injuries are the primary health problems for military personnel during military training $[12,13]$. Programs for prevention of musculoskeletal injuries are organized in armed forces of other countries [14-16]. Anthropometric parameters, such as increased body mass, are one of the risk factors for musculoskeletal disorders [17-19]. High physical load has influence on various health parameters [20]. High intensity exercises have influence on fat mass decreasing it. High physical load induces insulin sensitivity $[21,22]$. Anthropometric parameters like body mass, body mass index (BMI) are associated with health problems such as cardiovascular pathology, diabetes, cancer [23]. Changes of muscle characteristics are related to muscle strength [24]. BMI can be used for personnel selection according to physical fitness abilities, but in some cases BMI does not relate with military performance $[25,26]$. The aim of our study is to provide evaluation of posture analysis, foot status analysis, muscle function testing and assessment of anthropometric characteristics, which allows managing pre-courses training program for CTC participants to optimize adaptation to field conditions of military training.

\section{Material and methods}

Study group included 59 participants of Combat Training Course of both genders (47 males and 12 females) at the age of 22-30 years. We assessed readiness of cadets to high physical load during the CTC. According to the aim of the study, we carried out the following tasks: evaluation of posture status, analysis of anthropometric characteristics, checked such parameters of musculoskeletal system as muscle tone, muscle strength characteristics, and used Nordic Questionnaire list with a figure of Human Body, where a respondent marked the regions of musculoskeletal disorder (pain). All subjects gave their informed consent to the protocol approved by the local Medical Ethics Committee of the Riga Stradins University for biomedical research. The Combat training course lasts for ten days and includes various 


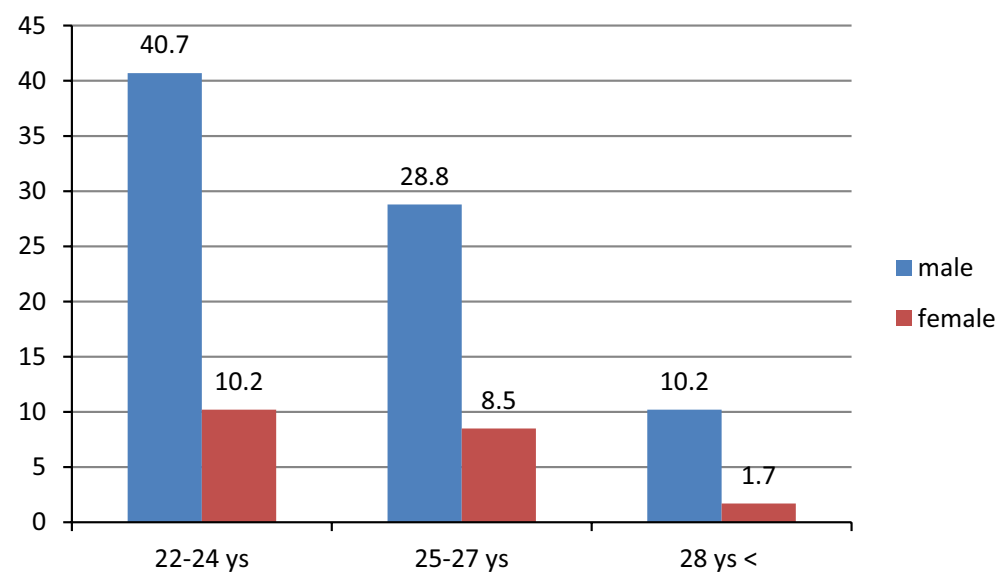

Fig. 1. Distribution of participants of Combat training course according to age and gender.

physical, tactical, and psychological activities in military conditions with equipment. Military training during the CTC was in combination with physical exertion, sleep restriction and dietary energy insufficiency. Cadets of CTC with full military equipment $(22.5 \mathrm{~kg})$ performed tactical exercises that included loaded road marches with obstacle course elements that were implemented during the CTC. Participants of CTC underwent medical examination programme by medical specialist in Medical Centre during the period of May-June, 2017. Sports medical doctor provided examination of posture status asymmetry (in frontal and sagittal planes), foot status analysis, muscle function testing (balance, coordination, elasticity tests) and assessment of anthropometric characteristics. The height was checked by anthropometry with an accuracy of $0.001 \mathrm{~m}$. The body weight was checked with scales with an accuracy of $0.01 \mathrm{~kg}$. The body mass indexes (BMI) were calculated as the quotient of body mass $(\mathrm{kg})$ and the square of height $\left(\mathrm{m}^{2}\right)$. Evaluation of health status of CTC participants allows managing pre-courses training program for CTC participants. We used standardized Nordic Questionnaire [27] for analysis and evaluation of musculoskeletal disorders in study group. The whole statistical analysis was performed in IBM SPSS Statistics 23 software. The Pearson's Chi-Square test was applied to examine the differences between the groups.

\section{Results}

Study group included 59 participants of both genders (47 males and 12 females) aged 22 to 30 years. Distribution of participants according to the age and genders are presented on (Fig. 1).

We used standardized Nordic Questionnaire for analysis and evaluation of musculoskeletal disorders in study group. Cadets indicated main problematic regions with musculoskeletal symptoms. The most problematic region was the back: $42.3 \%$ of respondents in study group indicated musculoskeletal symptoms in the lower back, $15.4 \%$ of respondents in the upper back and $21.1 \%$ of respondents - in the neck region. The next problematic region was lower extremities: $48.0 \%$ of respondents noted musculoskeletal symptoms in the knee region, and $11.5 \%$ of respondents indicated musculoskeletal disorders in the hip region and $17.3 \%$ of respondents - disorders in the foot region. Musculoskeletal symptoms in the upper extremities also were shown in standardized Nordic questionnaire data analysis: $34.6 \%$ of respondents mentioned musculoskeletal symptoms in the shoulder region, $15.4 \%$ of respondents noted musculoskeletal symptoms in the elbow region and $11.5 \%$ of respondents - 


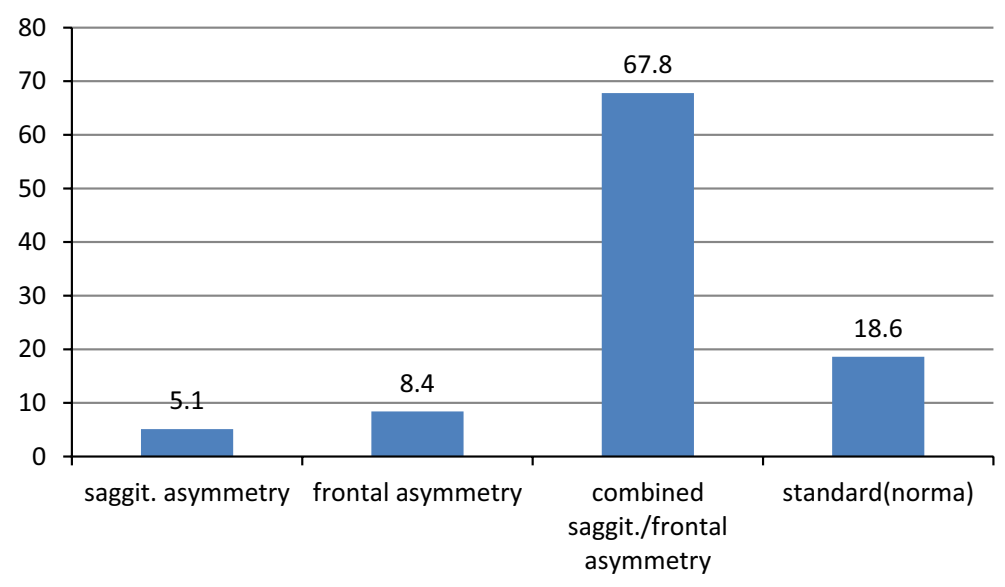

Fig. 2. Posture state assessment for participants of Combat training course.

in the wrist region. These musculoskeletal disorders were related with previous sports trauma, physical load and leisure time sports activities.

Posture analysis of participants was performed by Sports medicine doctor of Military Medical Centre in order to characterize functional status of musculoskeletal system, to reveal muscle over-stress and overload as well as posture disorders that can result in performance reduction during Combat training course.

Analysis revealed also posture problems: the combined asymmetric posture (in sagittal plane and frontal plane) was found in $67.8 \%$ (40/59) cadets. The asymmetric posture in one plane - sagittal plane was revealed in $5.1 \%(3 / 59)$ of cadets and the symmetric posture in frontal plane in $8.4 \%(5 / 59)$ of cadets of study group. 18.6\% (11/59) of cadets of study group had a normal standard posture.

Musculoskeletal complaints during the physical load were indicated by $25.4 \%$ (15/59) of participants of study group during Sports doctor's examination. Assessment of the foot status revealed foot asymmetry in $28.8 \%$ (17/59) of participants and deviation from standard weight distribution was found in $3.4 \%$ (2/59) of participants.

Increased level of muscle tone - hyper-tonus was fixed in $91.5 \%(54 / 59)$ of participants during examination tests. In 77\% (42/54) of cases, cadets with lower limb hyper-tone had asymmetric posture in frontal plane, but data between both groups are not statistically significant $(P>0.05)$. Examination of the coordination functional status of participants revealed that $32.2 \%(19 / 59)$ of respondents had dysfunctions and $25.4 \%$ (15/59) of participants had decreased level of elasticity. Evaluation of the balance status showed that $82 \%$ (37/45) of cadets with asymmetric posture in frontal plane had a balance disorder. Results of Sports doctor's examinations corresponded to standards (norm) and the rest part of participants of study group had dysfunction of balance characteristics.

Examination of the foot status showed the foot asymmetry in $28.8 \%(17 / 59)$ and deviation from standard weight distribution in $3.4 \%$ (2/59) of respondents.

Analysis of anthropometric characteristics showed that BMI changes were in the interval from 21.34 to 33.24. Anthropometric body mass and height parameters were used for calculation of the value of BMI. 30.5\% (14 males and 4 females) of participants had BMI value that corresponded to the standards (20-25 for males and 19-24 for females). $38.9 \%$ (20 males and 3 females) of participants had BMI value that exceeded standards by $10 \%$ (25-28 for males and 24-26 for females). 20.3\% (8 males and 3 females) of participants had BMI 


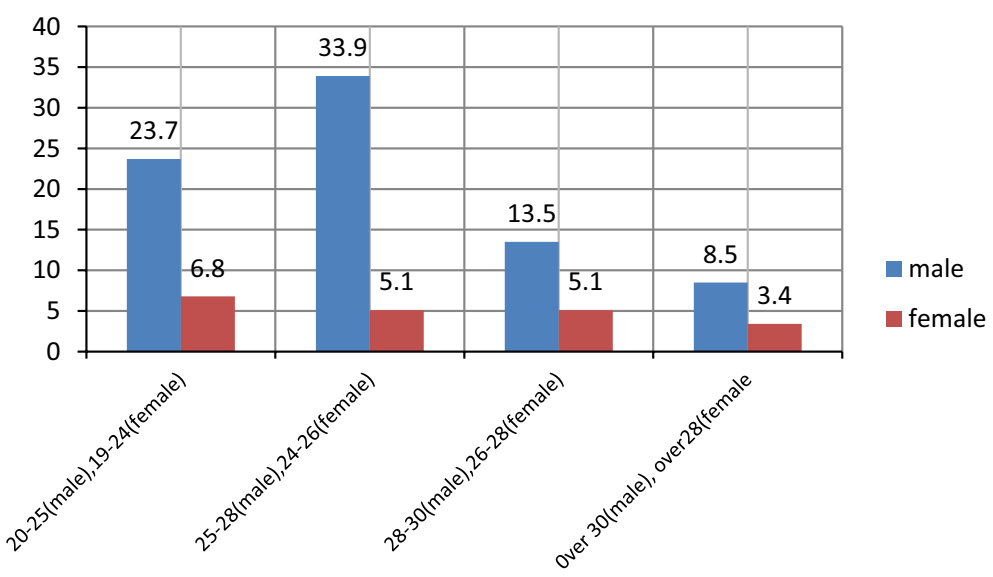

Fig. 3. Distribution of body mass index value for participants of CTC according to values and gender.

value over the standards by $20 \%$ (28-30 for males and 26-28 for females). For $11.9 \%$ (5 males and 2 females) of respondents BMI value was over the standards by $30 \%$ (over 30 for males and over 28 for females) (Fig. 3).

\section{Discussion}

Musculoskeletal disorders formed high morbidity rate among military personnel. According to data of Central Medical Expertise Commission, each third retired military person had musculoskeletal pathology that was acquired during military service. Military medical specialists should pay more attention to organizing the preventive measurement programme for diagnostics of early musculoskeletal dysfunctions. It allows reducing injury consequences and morbidity of military personnel. Standardized Nordic questionnaire for analysis of musculoskeletal symptoms revealed that in participants of the study group the most problematic regions were the back region (the lower back, the upper back and the neck region), then followed the lower extremity region (the knee, the hip and the foot region), and lastly the upper extremity (the shoulder, the elbow, the wrist region). Only $11.9 \%$ (7/59) of respondents in study group did not indicate any musculoskeletal symptoms. We have organized advanced medical examinations for participants of CTC, where participants faced high physical loads, and severe psychological stress conditions in military environment. During medical examination Sports medicine doctors found health problems and that will help to develop preventive procedures and special physical exercise program three months before starting Combat Training Course. 18.6\% (11/59) of participants of study group had posture status corresponding to standard. There were many participants with posture disorders in one plane (frontal and sagittal) and combined planes. The combined asymmetric posture (in sagittal plane and frontal plane) was found for $67.8 \%$ (40/59) of participants, the asymmetric posture in one plane - sagittal plane - was found for $5.1 \%$ (3/59) and the symmetric posture in frontal plane in $8.4 \%(5 / 59)$ of participants. $25.4 \%(15 / 59)$ of respondents indicated musculoskeletal complaints during the physical load. Early diagnostics is important for providing special sports exercise program for training of deep muscle groups with the aim to reduce musculoskeletal symptoms during high physical load for large number of participants with posture asymmetry. Assessment of functional tests revealed an increased level of lower limb muscle tone in $91.5 \%$ (54/59) cases. In 42 out of 52 cases 
cadets with lower limb hyper-tone had an asymmetric posture in frontal plane. Deviation of posture status from standards was the main risk factor in functional tests. Examination of the coordination status of participants of study group revealed that $32.2 \%$ (19/59) of respondents had dysfunctions. 25.4\% (15/59) of participants had decreased level of elasticity. Evaluation of the balance status of participants revealed that $18.6 \%$ (11/54) of respondents had balance disorders. We have found balance dysfunction for individuals with frontal posture asymmetry. Examination of the foot status showed the foot asymmetry for $28.8 \%$ (17/59) and deviation from standard weight distribution for 3.4\% (2/59) of respondents. Early diagnosis of foot disorders requires specialist's consultations, which would allow increasing elasticity and stability of foot during military tactical exercises. Assessment of anthropometric parameters, calculation of BMI showed that 30.5\% (14 males and 4 females) of participants of study group had BMI value that corresponded to the standards (20-25 for males and 19-24 for females). $38.9 \%$ (20 males and 3 females) of participants of study group had BMI value that exceeded standards by $10 \%$ (25-28 for males and 24-26 for females). $20.3 \%$ ( 8 males and 3 females) of participants had BMI value over the standards by $20 \%$ (28-30 for male and 26-28 for female). In $11.9 \%$ (5 males and 2 females) of respondents of study group BMI value was over standard by $30 \%$ (over 30 for males and over 28 for females). Increased values of BMI for military persons aged 22-30 did not have impact on military performance results, all participants of study group started Combat training course and all of them finished the course.

\section{Conclusion}

Analysis of posture and foot status was important for providing preventive measures and reduction of the risk of health disorders related to high physical load in military environment. Persons with expressed posture and foot asymmetry during dynamic load and static load can suffer from overstress with high risk of health disorders, musculoskeletal pathology and psychological overload.

\section{References}

[1] Hauschild V.D., DeGroot D.W., Hall S.M., Grier T.L., Deaver K.D., Hauret K.G., Jones B.H., Fitness tests and occupational tasks of military interest: a systematic review of correlations. Occup. Environ. Med. 74(2), 144-153 (2017) (http://dx.doi.org/10.1136/oemed-2016-103684)

[2] Nindl B.C, Billing D.C., Drain J.R., Beckner M. E., Greeves J., Groeller H., Teien H.K., Marcora S., Moffitt A., Reilly T., N.A.S., Young A.J., Friedl K.E., Perspectives on resilience for military readiness and preparedness: Report of an international military physiology roundtable. J. Sci. Med. Sport 21, 1116-1124 (2018) (https://doi.org/10.1016/j.jsams.2018.05.005)

[3] Burley S.D., Drain J.R., Sampson J.A., Groeller H., Positive, limited and negative responders: The variability in physical fitness adaptation to basic military training. J. Sci. Med. Sport 21, 1168-1172 (2018) (https://doi.org/10.1016/j.jsams . 2018.06.018)

[4] Blue M.N.M., Smith-Ryan A.E., Trexler E.T., Hirsch K.R., The effects of high intensity interval training on muscle size and quality in overweight and obese adults. J. Sci. Med. Sport. 21, 207-212 (2018) (https://doi.org/10.1016/j.jsams . 2017.06.001) 
[5] Knapik J.J., Sharp M.A., Canham-Chervak M., Risk factors for training related injuries among mem and women in basic combat training. Med. Sci. Sports \& Exercise 33(6), 946-954 (2001)

[6] Jones B.H. Bovee M.W., Harris J.M., Intrinsic risk factors for exercise-related injuries among male and female army trainees. Am. J. Sports Med. 21(5), 705-710 (1993) (https://doi.org/10.1177/036354659302100512)

[7] Roy T.C., Knapik J.J., Ritland B.M., Risk factors for musculoskeletal injuries for soldiers deployed to Afghanistan. Aviation, Space and Environ. Med. 83(11), 1060 1066 (2012) (https://doi .org/10.3357/ASEM . 3341.2012)

[8] Hynynen E., Uusitalo A., Kontinen N., Cardiac autonomic responses to standing up and cognitive task in overstrained athletes. Internat. J. Sports Med. 2997, 552-558 (2008) (https://doi .org/10.1055/s-2007-989286)

[9] Smith C.D., Cooper A.D., Merullo D.J., Sleep restriction and cognitive load after performance on a simulated marksman ship task. J. Sleep Res. (2017) (http://dx.doi.org/10.1111/jsr.12637)

[10] Liberman H.R., Castellani J.W., Young A.J., Cognitive function and mood during acute cold stress after extended military training and recovery. Aviation, Space and Environ. Med. 80(7), 629-636 (2009)

[11] Sawka M.N., Leon L.R., Montain S.J., Integrated physiological mechanisms of exercise performance, adaptation and maladaptation to heat stress. Comprehensive Physiology 1(4), 1883-1928 (2011)

[12] Wardle L.S., Greeves J.P., Mitigating the risk of musculoskeletal injury: A systematic review of the most effective injury prevention strategies for military personnel. Journal of Science and Medicine in Sport 20, S3-S10 (2017) (https://doi.org/10.1016/j.jsams.2017.09.014)

[13] Cameron K.L., Owens B.D., The burden and management of sports-related musculoskeletal injuries and conditions within the US military. Clin. Sports Med. 33(4), 573-589 (2014)

[14] Zambraski E.J., Yancosek K.E., Prevention and rehabilitation of musculoskeletal injuries during military operations and training. J. Strength and Conditioning Res. 26(2), S101-S106 (2012)

[15] Nindl B.C., Williams T.J., Deuster P.A., Strategies for optimizing military physical readiness and preventing musculoskeletal injuries in the 21 st century. US Army Medical Department Journal, pp. 5-23 (2013)

[16] Nindl B.C., Jaffin D.P., Dretsch M.N., Human performance optimization metrics: consensus findings, gaps, and recommendations for future research. J. Strength and Conditioning Res. 29(11), S221-S245 (2015) (https://doi.org/10.1519/ JSC.0000000000001114)

[17] Kyröläinen H., Pihlainen K., Vaara J.P., Ojanen T., Santtila M., Optimising training adaptations and performance in military environment. J. Sci. Med. Sport 21, 11311138 (2018) (https : //doi .org/10.1016/j.jsams.2017.11.019)

[18] Santtila M., Häkkinnen K., K. Karavirta I., Changes in cardiovascular performance during an 8-week military basic training period combined with added endurance or strength training. Military Med. 173(12), 1173-1179 (2008)

[19] Knapik J.J., Harman E.A., Steelman R.A., A systematic review of the effects of physical training on load carriage performance. J. Strength and Conditioning Res. 26(2), 585-597 (2012) (https://doi.org/ 10.1519/JSC. Ob013e3182429853)

[20] Boutcher S.H., Dunn S.L., Factors that may impede the weight loss response to exercise - based intervention. Obesity Reviews 10(6), 671-680 (2009) (https://doi.org/10.1111/j.1467-789X.2009.00621.x) 
[21] Boudou P., Sobngwi E., Mauvais-Jarvis F. Absence of exercise-induced variations in adiponectin levels despite decreased abdominal adiposity and improved insulin sensitivity in type 2 diabetic men, Eur. J. Endocrinol. 1149(5), 421-424 (2003) (https://doi.org/10.1038/sj.ijo.0803781)

[22] Trapp E., Heydari M., Freund J., The effects of high intensity intermittent exercise training on fat loss and fasting insulin levels of young women. Internal J. Obesity 32(4), 684-691 (2008) (https://doi.org/10.1038/sj.ijo.0803781)

[23] Bradshaw P.T., Monda K.L., Stevens J., Metabolic syndrome in healthy obese, overweight, and normal weight individuals: the arteriosclerosis risk in communities' study. Obesity 21(1), 203-210 (2012) (https : //doi.org/10.1002/oby . 20248)

[24] Cadore E.L., Gonzalez-Izal M., Pallares J.G., Muscle conduction velocity, strength, neural activity, and morphological changes after eccentric and concentric training. Scandinavian J. Med. Sci. Sports 24(5), e343-e352 (2014) (https://doi.org/ 10.1111/sms.12186)

[25] Sanderson P.W., Stacy A.C., Friedl K.E., Biddle S.J.H., The association between obesity related health risk and fitness test results in British Army personnel J. Sci. Med. Sport 21, 1173-1177 (2018) (https://doi.org/10.1016/j.jsams.2018. 08.003)

[26] Pierce J.R., DeGroot D.W., Grier T.L., Hauret K.G., Nindl B.C., East W.B., McGurk M.S., Jones B.H., Body mass index predicts selected physical fitness attributes but is not associated with performance on military relevant tasks in US. J. Sci. Med. Sport 20, S79-S84 (2017) (https://doi.org/10.1016/j.jsams . 2017.08.021)

[27] Kuorinka I., Jonsson B., Kilbom A., Vinterberg H., Biering-Søorensen F., Andersson G., Jøorgensen K., Standardised Nordic questionnaires for the analysis of musculoskeletal symptoms. Applied Ergonomics 18(3), 233-237 (1987) (https://doi.org/10.1016/0003-6870(87)90010-X)

[28] Maze R., Cavallaro G., Battling bureaucracy: the way forward requires modernizing the modernization process. Army Magazine 682018, 36-38 (2016) 